\title{
Prolificacy Study of Maize ( Zea mays L.) Inbred Lines and Hybrids on ARDS-Turda
}

\author{
Emilia TINCA ${ }^{1 *}$, Ioan HAȘ ${ }^{1,2}$, Ana COPÂNDEAN ${ }^{2}$ \\ ${ }^{1}$ University of Agricultural Sciences and Veterinary Medicine, Mănăştur Street, No. 3-5, 400372, Cluj- \\ Napoca, Cluj, Romania \\ ${ }^{2}$ Agricultural Research and Development Station (ARDS), Agriculturii Street, No. 27, Turda, Cluj, \\ Romania \\ *Corresponding author: emiliasuciu88@gmail.com
}

Bulletin USAMV series Agriculture 72(2)/2015

Print ISSN 1843-5246; Electronic ISSN 1843-5386

DOI 10.15835/buasvmcn-agr: 11464

\begin{abstract}
In 2014 year, an very favourable year for maize ( Zea mays L.) crops, were studied, in the Maize breeding laboratory from ARDS-Turda, eight maize inbred lines (four prolific and four non-prolific) and eight maize hybrids (four prolific and four non-prolific).Research aims were prolificacy study on three different culture densities and correlated traits. The study was carried out for three culture densities, first density- 40,000, second density60,000 , and third density- 80,000 plants/ha; there were determined the number of ears per plant, stalk breaking strength and crop yield production. For this study, the maize inbred lines and hybrids came from ARDS-Turda, from their own certified germplasm. The average amplitude of hybrids production ranged between $11,005 \mathrm{~kg} / \mathrm{ha}$ at 40,000 plants/ha density, and 12,531 kg/ha at 80,000 plants/ha. Highest grain yield value was registered in A 451-3 hybrid production, with $15,194 \mathrm{~kg} / \mathrm{ha}$ on 80,000 plants/ ha density. For the inbred lines average amplitude ranged between $5,355 \mathrm{~kg} /$ ha at 40,000 plants/ha density and 7,742 kg/ha at 80,000 plants/ha density. The highest grain yield value to the inbred lines was registered at TA 470 inbred line, with 9,925 kg/ha on 80,000 plants/ha density. The highest number of plant-ears was realized on A 451-3 hybrid with 2.6 ears on first density, 2.1 ears on second density and 1.6 ears/plant on third density. Also, the highest value for same character on inbred lines, was registered on PI 187, with 2.5 ears on first density and 2.0 ears on second and third densities. This research project suggest that prolificacy of maize inbred lines and hybrids is important for higher grain yield.Also the improved crop stand uniformity under lower densities is essential for stable grain yield per unit area.
\end{abstract}

Keywords: densities, grain yield, inbred lines, maize hybrids, prolificacy.

\section{INTRODUCTION}

Prolificacy in maize is an adaptability character, with influence on production capacity and production stability. Prolificacy is the maize (Zea mays $L$.) natural property to develop more cobs on the same plant. Prolific maize potential advantage, confirmed by many studies (Lee et al., 2005; Motto and Moll, 1983) pointed to a broad interest in prolific trait inheritance.

Several researchers have suggested that the potential for the plurality opinion cobs, can be inherited more easily than productivity.(Edwards,
2010; Tokatlidis et al., 2005).Edwards (2010) believes that maize production is the result of six components: the number of plants per unit area, number of cobs per plant, the number of rows of kernels on the cob, number of grains per row, the percentage of embryos per corn cob and 1000 grain mass. The aims of this study were to prove maize prolificacy for eight hybrids and eight inbred lines, and correlated traits, on three different culture densities. 


\section{MATERIALS AND METHODS}

For this experiment were chosen early maize genotypes, four prolific and four non-prolific, because it is known (Edwards, 2010) that between prolificacy and growing season is a correlation, meaning that early maize forms prove to be more prolific that the latter hybrids and inbred lines. Research objectives were:

- revealing secondary ear weighting (secondary cobs)on prolific hybrids in making grain production;

- studying the prolific and non - prolific forms to determine stalk breaking strength;

- determination of crop yield.

On this study the maize inbred lines and hybrids came from ARDS-Turda, from their own certified germplasm. The study was carried out on breeding fields from ARDS-Turda, for three culture densities, first density- 40,000 plants/ha, second density- 60,000 plants/ha, and third density80,000 plants/ha.
The method of settlement experience was randomized block, consisting of eight variants and two repetitions.

\section{RESULTS AND DISSCUSSION}

1.Revealing secondary ear weighting results

Analysing Tab. 1, which includes maize hybrids versions, we have to make several specifications:

- hybrids prolificacy is inversely proportional to the density of the plants;

- the top four prolificacy hybrids studied, maintain the character above the 1.5 level, even at high densities;

- the other four hybrids, do not show prolific character in terms of densities used in experiment.

In Tab. 2, we have noticed the secondary ear weighting, results of the year 2014 for inbred lines versions, which reveals that:

- prolific character for inbred lines which we studied, decreases with increasing plant density;

- inbred lines 1-4 variants, manifest and maintain prolific character even in high densities;

Tab. 1. Single and multiple-ear weighting on maize hybrids (\% corn cobs/ plant)

\begin{tabular}{ccccc}
\hline Version & Hybrid & $\begin{array}{c}\text { Density } 1 \\
(40.000 \mathrm{pl} / \mathrm{ha})\end{array}$ & $\begin{array}{c}\text { Density } 2 \\
(60.000 \mathrm{pl} . / \mathrm{ha})\end{array}$ & $\begin{array}{c}\text { Density } 3 \\
(80.000 \mathrm{pl} . / \mathrm{ha})\end{array}$ \\
\hline 1. & TE 330 x TA 452 & 2.4 & 2.0 & 1.6 \\
\hline 2. & TD 398 x TA 452 & 2.0 & 1.8 & 1.7 \\
\hline 3. & TA 451 x TA 452 & 2.6 & 2.1 & 1.6 \\
\hline 4. & Turda 228 & 2.2 & 1.5 & 1.4 \\
\hline 5. & TurdaFavorit & 1.5 & 1.1 & 1.0 \\
\hline 6. & Turda 248 & 1.1 & 1.0 & 1.0 \\
\hline 7. & Turda 332 & 1.3 & 1.0 & 1.1 \\
\hline 8. & Marius TD & 1.3 & 1.2 &
\end{tabular}

Tab. 2. Inbred lines secondary ear weighting (\% corn cobs/ plant)

\begin{tabular}{ccccc}
\hline Version & Inbred line & $\begin{array}{c}\text { Density } 1 \\
(40.000 \mathrm{pl} . / \mathrm{ha})\end{array}$ & $\begin{array}{c}\text { Density } 2 \\
(60.000 \mathrm{pl} . / \mathrm{ha})\end{array}$ & $\begin{array}{c}\text { Density } 3 \\
(80.000 \mathrm{pl} . / \mathrm{ha})\end{array}$ \\
\hline 1. & PI 187 & 2.5 & 2.0 & 2.0 \\
\hline 2. & TA 452 & 2.1 & 1.7 & 1.5 \\
\hline 3. & TA 470 & 2.4 & 1.9 & 1.6 \\
\hline 4. & TA 451 & 2.3 & 1.9 & 1.9 \\
\hline 5. & TE 382 & 1.9 & 1.2 & 1.0 \\
\hline 6. & TD 233 & 1.2 & 1.0 & 1.0 \\
\hline 7. & TC 344 & 1.3 & 1.0 & 1.0 \\
\hline 8. & TC 385A & 1.0 & 1.0 &
\end{tabular}


- 5-8 inbred lines do not exhibit variations in densities conditions applied.

\section{Stalk breaking strength and maize crop yield production results}

Knowing that the experimental year 2014, was a very favourable for crop yield production, we have to notice, following our study objectives, the next results:

- the average amplitude of hybrids production ranged between $11.005 \mathrm{~kg} /$ ha at 40.000 plants/ ha density, and $12.531 \mathrm{~kg} / \mathrm{ha}$ at 80.000 plants/ha.

- according table 3, highest grain yield value was registered in A 451-3(Turda228) hybrid production, with $15.194 \mathrm{~kg} / \mathrm{ha}$ on 80,000 plants/ ha density.

- the inbred lines average amplitude ranged between $5.355 \mathrm{~kg} / \mathrm{ha}$ at 40.000 plants / ha density and $7.742 \mathrm{~kg} / \mathrm{ha}$ at 80.000 plants/ha density.
- highest grain yield value of the inbred lines was registered, according to table 4 , at TA 470 inbred line, with $9.925 \mathrm{~kg} / \mathrm{ha}$ on 80.000 plants/ ha density.

An important aspect to note, is on the inbred line TA 451, on which was remarked the highest crop production on density of 80.000 plants/ ha, with $9.925 \mathrm{~kg} / \mathrm{ha}$, and on density of 60.000 plants/ha, reaching $9.704 \mathrm{~kg} / \mathrm{ha}$; also this inbred line has the best resistance at breaking stalk, with $100 \%$ unbreaked plants at all three densities.

\section{CONCLUSIONS}

During this experimental study, we suggest several main reasons for choosing the prolificacy character:

- as a valuable criterion in the improvement of maize grain yield, prolificacy received a special attention

Tab. 3. Hybrids average production at 3 culture densities, and unbreaked plants per unit area percentage average (Experimental year 2014 - ARDS-Turda)

\begin{tabular}{|c|c|c|c|c|}
\hline Version & Hybrid & Density & $\begin{array}{l}\text { Average production } \\
(\mathrm{kg} / \mathrm{ha})\end{array}$ & $\%$ unbreaked plants average \\
\hline \multirow{3}{*}{1.} & \multirow{3}{*}{ TE $330 \times$ TA 452} & D1 & 11005 & 86.96 \\
\hline & & $\mathrm{D} 2$ & 12417 & 92.78 \\
\hline & & D3 & 12531 & 90.84 \\
\hline \multirow{3}{*}{2.} & \multirow{3}{*}{ TD $398 \times$ TA 452} & D1 & 12858 & 86.88 \\
\hline & & D2 & 13732 & 86.36 \\
\hline & & D3 & 13327 & 86.84 \\
\hline \multirow{3}{*}{3.} & \multirow{3}{*}{ TA $451 \times$ TA 452} & $\mathrm{D} 1$ & 11211 & 75.21 \\
\hline & & $\mathrm{D} 2$ & 13622 & 91.02 \\
\hline & & D3 & 13493 & 95.38 \\
\hline \multirow{3}{*}{4.} & \multirow{3}{*}{ Turda 228} & D1 & 14455 & 92.85 \\
\hline & & D2 & 13878 & 96.47 \\
\hline & & D3 & 15194 & 97.35 \\
\hline \multirow{3}{*}{5.} & \multirow{3}{*}{ TurdaFavorit } & D1 & 8501 & 83.59 \\
\hline & & D2 & 8950 & 95.29 \\
\hline & & D3 & 9204 & 79.22 \\
\hline \multirow{3}{*}{6.} & \multirow{3}{*}{ Turda 248} & D1 & 9526 & 89.28 \\
\hline & & $\mathrm{D} 2$ & 10069 & 95.40 \\
\hline & & D3 & 11759 & 82.89 \\
\hline \multirow{3}{*}{7.} & \multirow{3}{*}{ Turda 332} & D1 & 9553 & 89.28 \\
\hline & & $\mathrm{D} 2$ & 11943 & 87.04 \\
\hline & & D3 & 10113 & 91.12 \\
\hline \multirow{3}{*}{8.} & \multirow{3}{*}{ Marius TD } & D1 & 11235 & 94.64 \\
\hline & & $\mathrm{D} 2$ & 14222 & 98.75 \\
\hline & & D3 & 13536 & 98.24 \\
\hline
\end{tabular}


Tab. 4. Inbred lines average production at 3 densities, and unbreaked plants per unit area percentage average(Experimental year 2014 - ARDS-Turda)

\begin{tabular}{|c|c|c|c|c|}
\hline Version & Inbred line & Density & $\begin{array}{c}\text { Average production } \\
(\mathrm{kg} / \mathrm{ha})\end{array}$ & $\begin{array}{c}\% \text { unbreaked } \\
\text { plants average }\end{array}$ \\
\hline \multirow{3}{*}{1.} & \multirow{3}{*}{ PI 187} & D1 & 5355 & 93.63 \\
\hline & & D2 & 7051 & 93.40 \\
\hline & & D3 & 7742 & 94.94 \\
\hline \multirow{3}{*}{2.} & \multirow{3}{*}{ TA 452} & D1 & 2046 & 83.59 \\
\hline & & D2 & 2820 & 84.82 \\
\hline & & D3 & 2816 & 82.64 \\
\hline \multirow{3}{*}{3.} & \multirow{3}{*}{ TA 470} & D1 & 7164 & 96.29 \\
\hline & & D2 & 8984 & 91.86 \\
\hline & & D3 & 8937 & 98.07 \\
\hline \multirow{3}{*}{4.} & \multirow{3}{*}{ TA 451} & D1 & 6503 & 100.00 \\
\hline & & D2 & 9704 & 100.00 \\
\hline & & D3 & 9925 & 100.00 \\
\hline \multirow{3}{*}{5.} & \multirow{3}{*}{ TE 382} & D1 & 7132 & 96.36 \\
\hline & & D2 & 8700 & 97.72 \\
\hline & & D3 & 9067 & 96.49 \\
\hline \multirow{3}{*}{6.} & \multirow{3}{*}{ TD 233} & D1 & 6284 & 98.00 \\
\hline & & D2 & 7555 & 100.00 \\
\hline & & D3 & 9146 & 98.11 \\
\hline \multirow{3}{*}{7.} & \multirow{3}{*}{ TC 344} & D1 & 3873 & 84.02 \\
\hline & & D2 & 5245 & 86.04 \\
\hline & & D3 & 6442 & 95.45 \\
\hline \multirow{3}{*}{8.} & \multirow{3}{*}{ TC $385 A$} & D1 & 4858 & 92.59 \\
\hline & & D2 & 6546 & 98.83 \\
\hline & & D3 & 7474 & 95.45 \\
\hline
\end{tabular}

in the ARDS-Turda environmental conditions, especially for average grain production;

- we recommend that farmers should found more attractive prolific genotypes, because it has positive influence on production capacity and production stability;also we suggest that the improved crop stand uniformity, under commercial or higher densities is essential for stable grain yield per unit area;

- although maize plants, special hybrids, initiate several ears, only one or two develop to maturity on high density conditions (60.00080.000 plants/ha); the maximum number of ears per stalk is determined both genetically and environmentally, whether it is hybrid or inbred line;

- even when plants are grown under favourable cultural conditions, we have revealed that on multiple-ear hybrids it decreases the size of the ears, comparing with single-ear hybrids; talking about inbred lines, the decrease in ear number and yield production per plant, is primarily the result of poor light due to shade from applying high culture densities $(80,000$ plants/ha).

\section{REFERENCES}

1. Edwards J (2010). Testcross response to four cycles of half-sib and S2 recurrent selection in the BS13 maize (Zea mays L.) population. Crop Science Vol. 50(5): 1840-1848.

2. Lee EA, Ahmadzadeah A, Tollenaar M (2005). Quantitative genetic analysis of the physiological processes underlying maize grain yield. Crop Science. Vol. 45(3): 981-987

3. Motto M, Moll RH (1983). Prolificacy in maize: a review. Maydica XXVIII: 53-76.

4. Tokatlidis IS, Koutsika-Sotiriou M, Tamoutsidis E (2005). Benefits from using maize density-independent hybrids, Maydica 50: 9-17. 